\title{
Histologic and molecular diagnosis of tularemia: a potential bioterrorism agent endemic to North America
}

\author{
Laura W Lamps ${ }^{1}$, Jennifer M Havens ${ }^{1}$, Anders Sjostedt ${ }^{2}$, David L Page ${ }^{3}$ and \\ Margie A Scott ${ }^{1,4}$ \\ ${ }^{1}$ Department of Pathology, University of Arkansas for Medical Sciences, Little Rock, AR, USA; ${ }^{2}$ Department of \\ Clinical Microbiology, University of Umea, Umea, Sweden; ${ }^{3}$ Department of Pathology, Vanderbilt University \\ School of Medicine, Nashville, TN, USA and ${ }^{4}$ Department of Pathology, Central Arkansas Veterans' \\ Healthcare System, Little Rock, AR, USA
}

\begin{abstract}
Francisella tularensis (FT), a zoonotic bacterium that causes tularemia, has received attention as a possible bioterrorism threat. We developed a PCR assay for use in fixed, processed tissues, which are safer to handle and allow archival testing. PCR analysis for a 211-bp fragment of the FT lipoprotein gene was performed on tissues from 16 cases of tularemia. In all, 14/15 cases with intact DNA (93\%) were positive for FT by PCR. Frequent histologic findings in PCR-positive tissues included irregular microabscesses and granulomas in liver, spleen, kidney, and lymph nodes, and necrotizing pneumonia. Unusual cases featuring suppurative leptomeningitis and gastrointestinal ulcers were also seen. As this disease is endemic in North America, and has been identified as a potential bioterroristic threat, awareness of the clinicopathologic spectrum of disease and available detection methods is increasingly important. This PCR assay, the first designed for use in processed tissues, is an excellent method for diagnosis of tularemia.

Modern Pathology (2004) 17, 489-495, advance online publication, 5 March 2004; doi:10.1038/modpathol.3800087
\end{abstract}

Keywords: Francisella tularensis; tularemia; polymerase chain reaction; tick-borne; bioterrorism; molecular diagnosis; immunohistochemistry

Francisella tularensis (FT) is a Gram-negative bacterium that causes the disease tularemia; it is endemic in North America as well as parts of Europe and Asia. ${ }^{1-6}$ This zoonotic bacterium is associated with arthropod vectors, and both wild and domestic animals (particularly cats that have eaten infected rodents or rabbits); transmission through water contaminated by infected rodents has also occurred. ${ }^{2,7}$ Most human infections are acquired from arthropod bites, exposure to infected animals from skinning and dressing game, or inhalation of contaminated dust, dirt, and lawn clippings. ${ }^{4,7-9} \mathrm{Re}-$ gardless of the mode of acquisition, tularemia is a serious and often fatal disease.

There are two main subtypes of FT: the more virulent Jellison type A or biovar tularensis is found almost exclusively in North America, whereas

Correspondence: Dr LW Lamps, Deptartment of Pathology, University of Arkansas for Medical Sciences, 4301 W. Markham Street, Slot 517, Little Rock, AR 72205, USA.

E-mail: lampslauraw@uams.edu

Received 13 August 2003; revised 18 December 2003; accepted 22 December 2003; published online 5 March 2004
Jellison type B or biovar palaearctica is found most commonly in Asia and Europe and to a lesser extent in North America. ${ }^{10,11}$ Approximately 200 cases per year are reported to the Centers for Disease Control and Prevention (CDC), mostly from the south-central United States. ${ }^{4-6}$ However, FT has recently received an increased amount of attention as a Category A potential agent of bioterrorism, along with anthrax, smallpox, viral hemorrhagic fevers, and Yersinia pestis., ${ }^{1,42}$ Owing to the high risk of inhalational infection from even low numbers of organisms (1025 organisms required to produce disease by aerosol delivery), and a high mortality rate $(30-60 \%$ for untreated inhalational FT), tularemia could potentially be a very effective bioterroristic weapon. . $^{1,4,10,13,14}$

The clinical diagnosis of tularemia is difficult, as symptoms are nonspecific and often initially resemble influenza or other respiratory tract infections. Laboratory diagnosis is also problematic. Due to the fastidious nature of this slow-growing organism, and more importantly the high risk of inhalational infection to laboratory personnel, culture techniques are difficult to perform and often 
avoided. ${ }^{3,14}$ Serologic studies (including ELISA and agglutination assays) are the most common methods employed for diagnosis, but antibody is not usually detectable until the second week of the disease, and crossreactivity with other organisms remains an issue. ${ }^{1,2,10,14-16}$ Immunohistochemical studies, fluorescent antigen testing, and immunoelectron microscopy have also been used to detect FT, but these methods have very limited availability. ${ }^{2,9}$ Although effective antibiotic treatment is available, mortality increases dramatically with delayed diagnosis, thus rapid, sensitive, and specific detection methods that facilitate early diagnosis are critical.

A limited number of previous studies performed in Europe and Asia have shown that polymerase chain reaction (PCR) amplification of FT DNA in fresh tissues is a sensitive and specific diagnostic test. ${ }^{10,14,17-21}$ Our goal was to develop a PCR assay that could be used in formalin-fixed, routinely processed tissues, which are (1) safer to handle and (2) allow diagnostic testing even after fixation and processing. We then compared the clinical and pathologic findings with the molecular data.

\section{Materials and methods}

In all, 16 cases of clinically suspected, naturally occurring tularemia were evaluated, including 10 human specimens (seven autopsy and three biopsy) and six animal autopsies (five non-human primate and one feline). The six animal cases and three biopsy cases are courtesy of the CDC and were immunohistochemically confirmed there; ${ }^{9}$ the seven human autopsy cases were retrieved from the archives of Vanderbilt University and were also immunohistochemically confirmed courtesy of the CDC. Multiple tissue types were evaluated histologically and by PCR, including lymph node, liver, spleen, kidney, heart, lung, meninges, and gut. Although three cases had reported skin lesions, no tissue from the lesions was available for analysis. Histochemical stains such as Gram or Steiner silver impregnation methods were not performed, owing to the low yield previously reported with such stains. ${ }^{2,9,22,23}$

\section{Molecular Analysis}

All cases were analyzed in the same laboratory, the Infectious Disease Molecular Research Laboratory at the University of Arkansas for Medical Sciences. DNA was extracted from two $25 \mu \mathrm{m}$ sections of formalin-fixed, routinely processed, paraffinembedded lesional tissue. The tissue was subjected to overnight digestion at $55^{\circ} \mathrm{C}$ with proteinase $\mathrm{K}$ following deparaffinization. Extracted DNA was captured by overnight incubation at room temperature in a silica matrix with sodium iodide. Primers were $5^{\prime}$ end-labeled with gamma ${ }^{32} \mathrm{P}$ adenosine triphosphate, and DNA amplification was performed by PCR using previously published primers for a 211-bp fragment of the $17 \mathrm{kDa}$ FT Tul4 lipoprotein gene, ${ }^{8,10}$ present in both biovars of $\mathrm{FT}^{8,10,14,24}$ Pure lyophilized genomic DNA served as a positive control. Reagent blanks were used as negative controls. Size separation of amplicons was performed on $8 \%$ polyacrylamide gel followed by gel drying and autoradiography. PCR analysis of all samples was performed at least in duplicate. Amplification of the similarly sized (99-bp) $\beta$-actin housekeeping gene was performed on all samples to ensure the presence of intact DNA.

\section{Limits of Detection and Specificity of PCR Assay}

Purified genomic DNA derived from pure cultures and tissues containing multiple species of bacteria (including Yersinia species, Mycobacterium tuberculosis, 11 species of atypical mycobacteria, and Leptospira) were evaluated to ensure specificity. Similar studies with other bacteria, including Pseudomonas, Serratia, Brucella, Providencia, Enterobacter, Klebsiella, Salmonella, Bacillus anthracis, Escherichia coli, Vibrio cholerae, Shigella, Legionella, and Proteus species have been previously performed using these primers. ${ }^{8,10}$ The results of these studies showed no nonspecific amplification; thus, there is no known nonspecific annealing with DNA from other bacteria. In addition, sequencing analysis was performed on specimens positive for FT by PCR. Sequences generated from our PCR products were homologous to published sequences for the gene segments we amplified.

The limits of detection of the assay were determined by limiting dilution PCR using serial dilutions of pure genomic FT DNA. Amplicons were excised from the gel, extracted, and DNA quantitation was confirmed by spectrometer. A PCR product could be detected from amplicons containing a lower limit of approximately 10 copies of the Tul4 gene. ${ }^{24}$ However, it is recognized that limits of detection determined with purified DNA may not correlate exactly with that of extracted DNA from archival tissue.

\section{Clinical Data}

At least partial records were available in all cases. Records were reviewed with attention to age, gender, serologic studies, culture results, exposure history, clinical presentation, and clinical course.

\section{Results}

\section{Molecular Analysis}

Of the 16 cases, 15 had intact DNA by analysis of the $\beta$-actin housekeeping gene; of these, 14 (93\%) were positive for FT DNA by PCR analysis (Image 1). All reagent blanks and FT-negative control cases were appropriately negative. FT DNA was detected in all types of tissues tested, including lymph node, liver, spleen, kidney, heart, lung, meninges, and gut. 


\section{Histopathology}

All of the human cases had lymph nodes available for evaluation, whereas the animal necropsies did not. Evaluation of the nodes showed involvement in all cases. Most were grossly necrotic, and histologic lesions ranged from well-defined zones (either smooth-bordered or irregular) of acute inflammation and necrosis located within the outer cortex (Image $2 \mathrm{a}, \mathrm{b})$, to generalized necrosis that virtually obliterated the node. Rare nodes also contained granulomatous inflammation. Of the nine cases where lung was available for evaluation, eight had necrotizing pneumonia characterized by abundant fibrin, cellular debris, and neutrophils within alveolar walls and alveolar spaces (Image 3), accompanied by edema. Confluent areas of necrosis obliterating all normal architecture were also observed. Three cases also had an associated marked suppurative pleuritis. Of the 11 cases (both human and animal) from which liver and spleen were submitted, all had microabscesses, with either rounded (Image 4) or irregular outlines, often with central necrosis. Two cases showed confluence of lesions and more extensive parenchymal necrosis. Gross pathological descriptions of the liver and spleen were available in five cases, featuring hepatosplenomegaly with grossly visible small (1-2 mm), often necrotic nodules. More unusual histologic findings included suppurative leptomeningitis (Image 5) and ulcerative lesions (three cases) of the small and large bowel (Image 6), consisting of punched-out areas of mucosal ulceration and necrotic debris overlying an ulcer bed containing numerous neutrophils.

\section{Clinical Data}

A summary of the clinical data from human cases is given in Table 1. In humans (four male, five female, unknown gender in one), age ranged from 6 to 65 years (median 28). Exposures included skinning

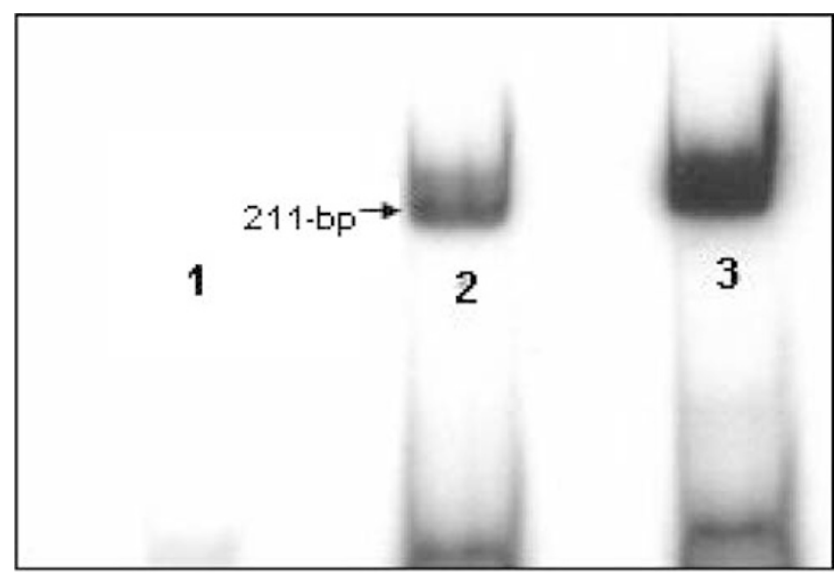

Image 1 PCR gel showing negative control (lane 1); Positive case (liver tissue) for the 211-bp fragment of the Tul4 lipoprotein gene of FT (lane 2); positive control of killed lyophilized FT DNA (lane 3).
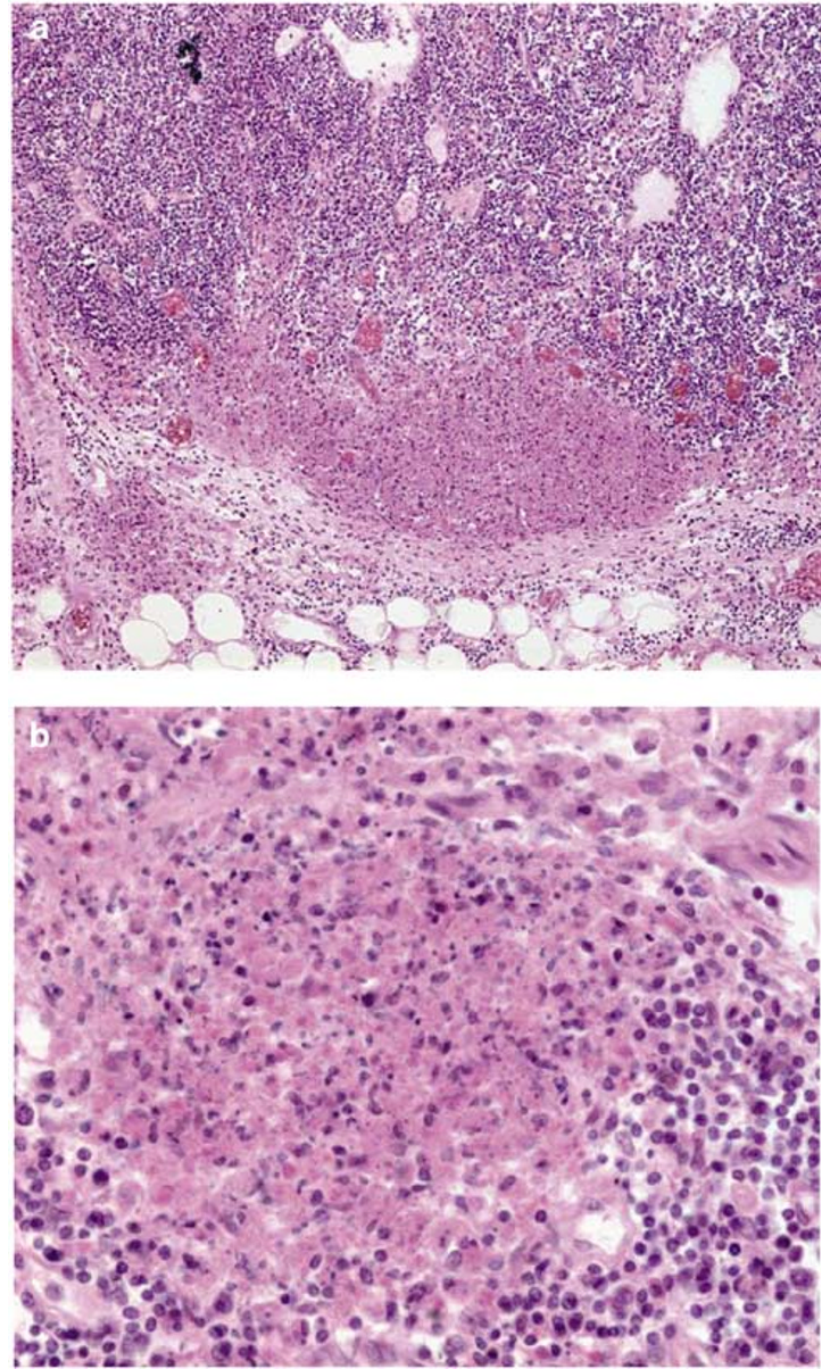

Image 2 Lymph nodes show well-defined zones of necrosis, predominantly in the outer cortex (a): H\&E, original magnification $\times 100$; (b): H\&E, original magnification $\times 400$ ).

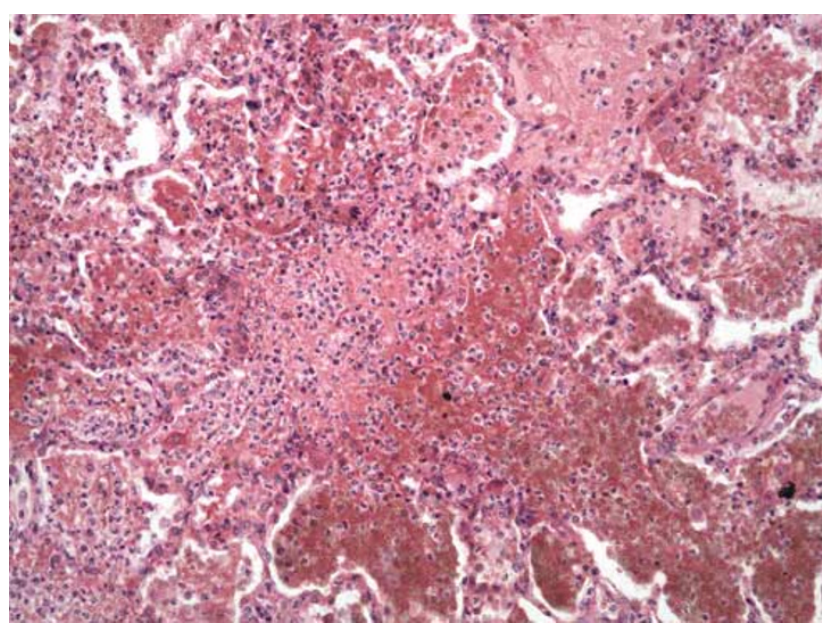

Image 3 The most common pulmonary histologic finding was suppurative pneumonia with areas of necrosis and hemorrhage (H\&E, original magnification $\times 200$ ). 


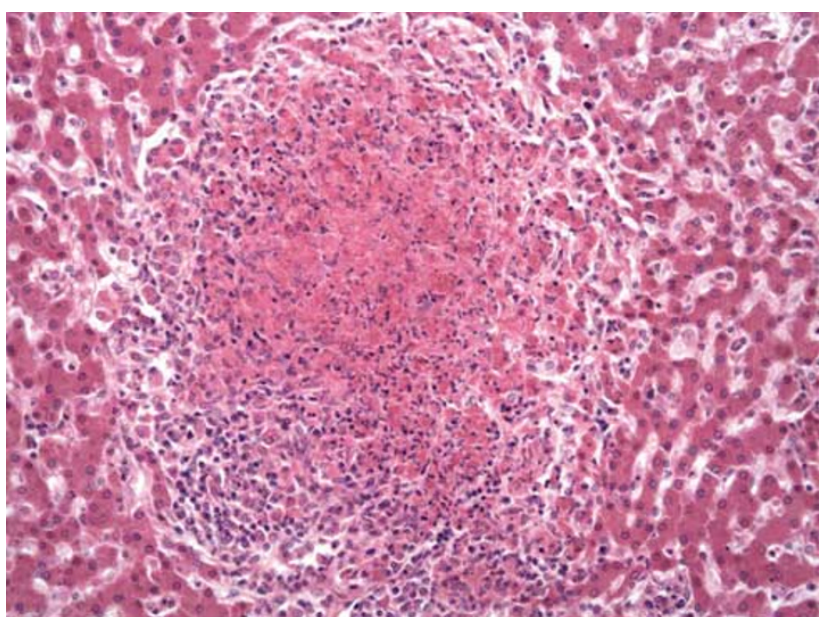

Image 4 Sections of liver showed rounded microabscesses ( $\mathrm{H} \& \mathrm{E}$, original magnification $\times 200$ ).
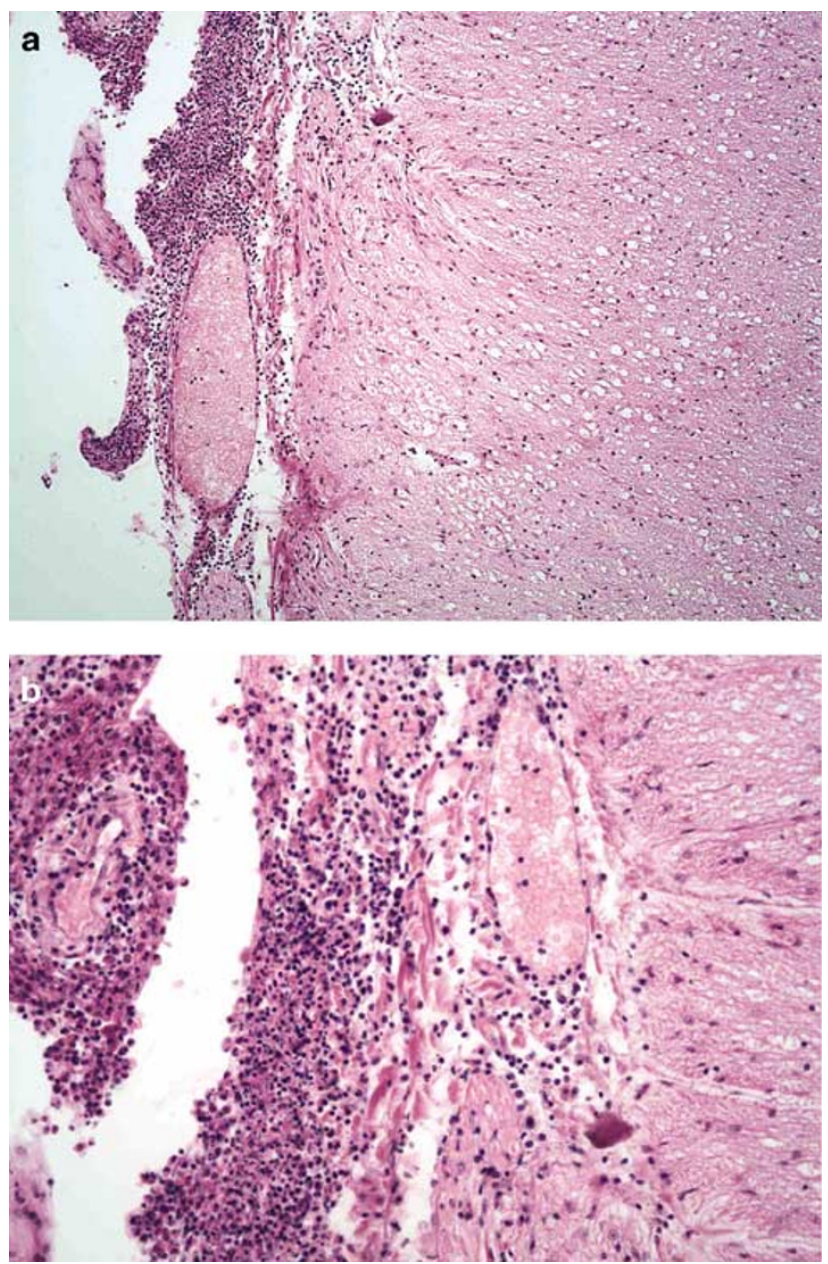

Image 5 Leptomeningitis (tissue positive for FT DNA by PCR) was seen in one patient $(\mathbf{a})$ : $H \& E$, original magnification $\times 100$; (b): H\&E, original magnification $\times 200$ ).

rabbits (three), tick bite (one), residence in area of previous known outbreak (three), and unknown in the other humans and in the animals. Serologic

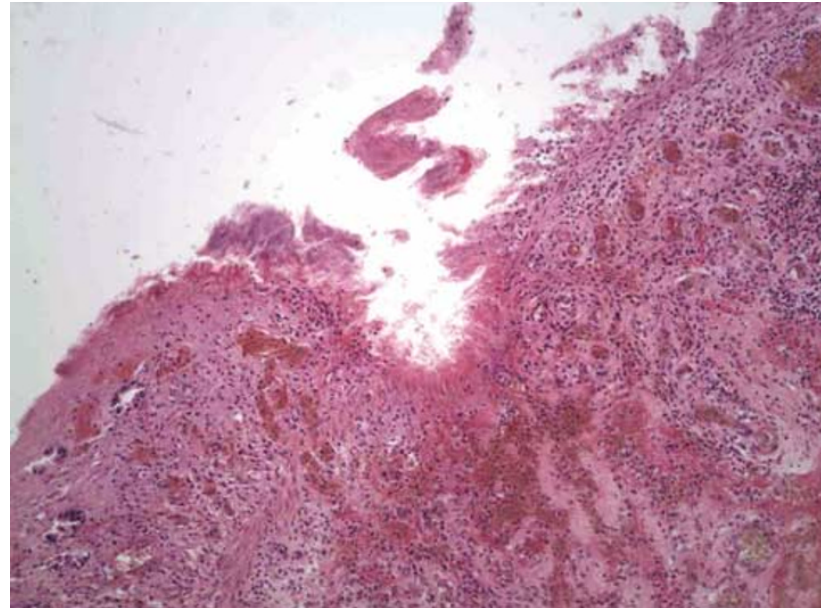

Image 6 Ulcerative colonic lesions (tissue positive for FT DNA by PCR) were observed in rare cases, consisting of necrotic ulcer debris overlying a dense neutrophilic infiltrate (H\&E, original magnification $\times 100$ ) .

studies were positive in four cases, and cultures were positive in seven cases. The range of presenting signs and symptoms were extremely variable. Fever, often very high (104-105 $)$ and accompanied by chills, was the most constant feature, followed by malaise, respiratory symptoms, headache, and delirium. Four patients had skin lesions (two had skinned rabbits, one tick bite, and one cut herself performing chores outside), and eight had lymphadenopathy. Of note, three patients had prominent gastrointestinal symptoms, and one had meningeal signs. The five non-human primates and the cat presented in septic shock; all six animal cases were fatal.

\section{Discussion}

Although previous studies have demonstrated the utility of PCR assays in analyzing blood samples, swabs from ulcerative lesions, and pus for the presence of FT DNA, , ${ }^{8,10,11,14,17-21}$ we describe the first PCR assay designed for use in formalin fixed, routinely processed, archival tissues. Our findings indicate that PCR of processed tissues is a safe, rapid, sensitive, and specific method for the detection of FT in both human and animal tissues. In the single immunohistochemically confirmed case that was negative by PCR, the immunohistochemical confirmation was performed prior to PCR, and the lesion was almost entirely cut through when the sample was received for molecular analysis; thus the negative result may represent lack of lesional tissue containing organisms.

The public, in general, is not aware of tularemia as a potential health concern. In nature it is a sporadic, endemic disease that more often affects individual patients, separated both geographically and temporally, rather than large groups of people simultaneously. However, it is the third most common 
Table 1 Human tularemia cases: summary of clinical data

\begin{tabular}{|c|c|c|c|}
\hline Case \# & Age (years)/sex & Exposure & Clinical history \\
\hline 1 & $18 / \mathrm{M}$ & Skinned rabbit & Febrile illness with pneumonia, pleural effusion, diarrhea; fatal \\
\hline 2 & $65 / \mathrm{M}$ & Skinned rabbit & Hand ulcer with subsequent febrile illness, pneumonia; fatal \\
\hline 3 & $6 / \mathrm{F}$ & Tick bite & Ulcerated skin papule, rash, meningeal signs and seizures; fatal \\
\hline 4 & $45 / \mathrm{F}$ & $\begin{array}{l}\text { Cut hand working outside, } \\
\text { endemic area }\end{array}$ & Febrile illness with nausea and vomiting; became comatose; fatal \\
\hline 5 & $19 / \mathrm{F}$ & $\begin{array}{l}\text { ?Drank stream water \& } \\
\text { unpasteurized milk, endemic } \\
\text { area }\end{array}$ & Febrile illness with respiratory distress, headache, delirium; fatal \\
\hline 6 & $52 / \mathrm{F}$ & Unknown & $\begin{array}{l}\text { Febrile illness with malaise, nausea, vomiting, became comatose } \\
\text { and died }\end{array}$ \\
\hline $7^{\mathrm{a}}$ & $21 / \mathrm{F}$ & Unknown & Febrile illness with lymphadenopathy; survived \\
\hline 8 & $28 / \mathrm{M}$ & Endemic area & Flu-like illness with diarrhea, progressed to sepsis and death \\
\hline $9^{\mathrm{a}}$ & $40 / \mathrm{M}$ & Skinned rabbit & Febrile illness with skin lesions, lymphadenopathy; survived \\
\hline $10^{\mathrm{a}}$ & Adult/unknown & Unknown & Unknown history; lymph node biopsy; survived \\
\hline
\end{tabular}

${ }^{\mathrm{a}}$ Case courtesy of CDC.

tick-borne disease in the United States. ${ }^{1}$ It has been found in every state in America except Hawaii (with Arkansas, South Dakota, Missouri, and Oklahoma considered major endemic areas), as well as in Scandinavia, Asia, and Canada. ${ }^{1,3,4}$ Although the number of cases in the United States has declined since the mid-1900s, many authorities think that tularemia is both markedly under-recognized and under-reported..$^{1,3-6,16}$

Tularemia affects over 250 mammalian species including humans, and has also been found in invertebrates, water, mud, and feces. ${ }^{1,3,17,25}$ Exposure from animals occurs primarily through skinning and dressing game, but ingesting contaminated meat and animal bites may also cause disease. ${ }^{2}$ Arthropod vectors are extremely important, for many species of tick, flea, mosquito, and biting fly are known to transmit tularemia. ${ }^{1}$ Inhalational outbreaks have been linked to lawn mowing and brush cutting, when presumably rodent and rabbit feces contaminated by FT are aerosolized. ${ }^{4,7,26,27}$ Our cases reflect the multiple modes of transmission of tularemia, including arthropod bite, skinning game, exposure to presumably contaminated stream water, and living in known endemic areas with contaminated soil.

In addition to its widespread presence in nature, tularemia is the second most common laboratoryassociated infection in American and the third worldwide. ${ }^{28}$ As FT colonies can be misidentified as similar bacteria (such as Legionella, Y. pestis, Brucella, and Hemophilus influenza) during initial workup, proper precautions for laboratory staff may not be taken. ${ }^{1,28}$ The ease with which laboratory workers may contract inhalational tularemia, as well as cutaneous disease acquired from handling specimens and transmitting the organism through small breaks in the skin, has implications for processing specimens from both naturally acquired and potentially deliberate outbreaks. ${ }^{1,2,3,7,10,14,28}$

Tularemia has traditionally been divided into six clinical types; due to the great deal of overlap between them, classification has recently been simplified into ulceroglandular or typhoidal/septic types. ${ }^{1,29,30}$ Regardless of clinical type, most cases have some degree of pulmonary involvement, and over $10 \%$ go on to develop ARDS. ${ }^{1,31}$ Typical symptoms and physical findings include fever (often high with chills), cutaneous ulcers, lymphadenopathy, headache, malaise, and fatigue; less common signs and symptoms include cough, sore throat, myalgias, chest pain, nausea, vomiting, diarrhea, and mental status changes. ${ }^{1,5,16}$ The onset of symptoms is typically acute, following an average incubation period of 2-5 days (range 1-21 days). ${ }^{1,2,7}$ Mortality in general is less than $10 \%$ with treatment; however, it increases dramatically to $30-60 \%$ if untreated, or if there is significant pulmonary involvement. ${ }^{4,32}$ Factors associated with increased mortality include delayed or inappropriate antibiotic therapy, underlying medical problems, and positive blood cultures., ${ }^{2,33}$ Our clinical data are biased towards severe cases since this is primarily an autopsy/necropsy study. Of note, all of the animal cases presented with septic shock and were fatal. In the human cases, five presented with ulceroglandular or glandular features, and of these three survived. The remainder presented with significant pulmonary involvement and/or signs of systemic illness; all of these cases were fatal. This supports previous literature indicating that once the lungs are severely involved and/or systemic disease is present, mortality is dramatically increased in both humans and animals.

The pathology of the liver, spleen, lymph node, and pulmonary tissues in our cases were very similar to histologic features described by previous authors in both humans and animals. ${ }^{1,2,32,34,35}$ Our cases also illustrate that in addition to classical nodal and pulmonary involvement, tularemia usually affects the liver and spleen with hepatosplenomegaly and necrotic lesions visible on gross examination. In addition, pathologists should be 
aware that tularemia can cause atypical lesions such as suppurative leptomeningitis or ulcers anywhere in the gastrointestinal tract. Although rarely reported in the literature,,$^{3,23,36}$ gastrointestinal and neurologic symptoms may dominate the presentation of FT infection, and pulmonary findings may be absent, particularly early in the course of disease.

Laboratory diagnosis of tularemia has historically been challenging. In the literature, cultures are only positive in $5 \%$ of cases overall, ${ }^{1}$ and growth of this fastidious organism requires enriched media, a narrow zone of optimal temperature, and a large inoculum. ${ }^{3,8,14}$ Although a four-fold elevation in serologic titers remains the most common diagnostic method, there are numerous problems with serologic assays regardless of test methodology. Antibody is not usually detectable until the second week of the disease, and sometimes not until the fourth week..$^{1,2,15,16}$ Antibody may persist for over 10 years, requiring acute and convalescent titers to confirm current infections. ${ }^{1}$ Crossreactivity with other organisms (including Brucella, Proteus, and Yersinia species) is also problematic. ${ }^{10,14,15}$ A skin test for FT exists in limited availability; however, it may take up to $2-4$ weeks to detect a positive result, and reactivity may persist for up to 40 years. ${ }^{1,2,37}$ Immunohistochemical studies, fluorescent antigen testing, and immunoelectron microscopy have also been used to diagnose FT, but none of these methods are widely available, and some (such as the immunohistochemical assay used to confirm our methodology) are only available through the CDC or the US military. ${ }^{9}$ Thus, our PCR assay is an excellent technique for the detection of FT in archival tissues as it appears to be both sensitive and specific, with no demonstrated nonspecific amplification of similar pathogens. ${ }^{10}$ In addition, it is much safer for laboratory workers, as handling of blood, wound material, or culture plates is not necessary. This is the first PCR assay for FT designed for use in formalin-fixed, routinely processed, paraffinembedded tissues; our primer target size of less than 400-bp is ideal for use with processed tissues, and the use of a resin rather than phenol for extraction of DNA from archival tissues produces a higher yield of intact DNA for amplification.

Tularemia was first recognized as a potential agent of bioterrorism in the 1950s, when it was evaluated by both the United States and the USSR for use in biologic weapons programs. ${ }^{3}$ It has recently been classified as a Category A agent of potential bioterrorism..$^{4,12,13,28,38}$ Due to its virulence and relatively short incubation period, a deliberately caused outbreak of tularemia could conceivably affect a large population within less than a week. ${ }^{1,4,13}$ Factors adding to the concern include its widespread presence in nature within a myriad of hosts, in addition to the serious risks posed to laboratory personnel. Should a deliberate outbreak of tularemia occur, a PCR assay that can be used in processed tissues could potentially play a valuable role in case confirmation, as diagnosis by at least two methods is usually required if culture is not available.

FT is an important naturally occurring infection that is widespread in nature,,$^{1,3,17,25}$ as well as a potential bioterrorism threat. Awareness of the spectrum of disease that it causes, as well as available detection methods, is important to pathologists and laboratory personnel. Since special stains, cultures, and serologic assays are often nondiagnostic or cause delays in diagnosis, PCR analysis is an excellent technique for the diagnosis of tularemia in human and animal tissues.

\section{Acknowledgements}

We gratefully acknowledge Drs Wun-Ju Shieh, Jeannette Guarner, and Sherif Zaki along with the Centers for Disease Control and Prevention for their generous donation and immunohistochemical confirmation of cases, as well as their consultative expertise. In addition, we gratefully acknowledge the partial funding provided by the University of Arkansas Medical Research Endowment Fund, Ed Harms Family Research Award.

\section{References}

1 Martin GJ, Marty AM. Clinicopathologic aspects of bacterial agents. Clin Lab Med 2001;221:513-548.

2 Geyer SJ, Burkey A, Chandler FW. Tularemia. In: Connor DH, Chandler FW (eds). Pathology of Infectious Diseases. Appleton and Lange: Stamford, CT, 1997, pp 869-873.

3 Ellis J, Oyston PCF, Green M, et al. Tularemia. Clin Microbiol Rev 2002;15:631-646.

4 Anonymous. Tularemia-United States, 1990-2000. MMWR 2002;51::181-184.

5 Taylor JP, Istre GR, McChesney TC, et al. Epidemiologic characteristics of human tularemia in the southwestcentral United States. Am J Epidemiol 1991;133:10321038.

6 Burgdorfer W, Cooney JC, Thomas LA. Zoonotic potential (Rocky Mountain spotted fever and tularemia) in the Tennessee Valley region. Am J Trop Med Hyg 1974;23:109-117.

7 Altman GB. Tularemia. A pathogen in nature and a biological weapon. AAOHN J 2002;50:373-377.

8 Sjostedt A, Eriksson U, Berglund L, et al. Detection of F. tularensis in ulcers of patients with tularemia by PCR. J Clin Microbiol 1997;35:1045-1048.

9 Guarner J, Greer PW, Bartlett J, et al. Immunohistochemical detection of Francisella tularensis in formalin-fixed, paraffin-embedded tissue. Appl Immunol Mol Morphol 1999;7:122-126.

10 Junhui Z, Ruifu Y, Jianchun L, et al. Detection of $F$. tularensis by the polymerase chain reaction. J Med Microbiol 1996;45:477-482.

11 Johansson A, Ibrahim A, Goransson I, et al. Evaluation of PCR-based methods for discrimination of Francisella species and subspecies and development of a specific 
PCR that distinguishes the two major subspecies of F. tularensis. J Clin Micro 2000;38:4180-4185.

12 Broussard LA. Biological agents: weapons of warfare and bioterrorism. Mol Diagn 2001;6:323-333.

13 Anonymous. Recognition of illness associated with the intentional release of a biologic agent. MMWR Wkly 2001;50:893-897.

14 Fulop M, Leslie D, Titball R. A rapid, highly sensitive method for the detection of $F$. tularensis in clinical samples using the polymerase chain reaction. Am J Trop Med Hyg 1996;54:364-366.

15 Sato T, Fujita H, Ohara Y, et al. Microagglutination test for early and specific serodiagnosis of tularemia. J Clin Microbiol 1990;28:2372-2374.

16 Jacobs RF, Condrey YM, Yamauchi T. Tularemia in adults and children: a changing presentation. Pediatrics 1985;76:818-822.

17 Farlow J, Smith KL, Wong J, et al. F. tularensis strain typing using multiple-locus, variable number tandem repeat analysis. J Clin Microbol 2001;39: 3186-3192.

18 Higgins JA, Hubalek Z, Halouzka J, et al. Detection of F. tularensis in infected mammals and vectors using a probe based PCR reaction. Am J Trop Med Hyg 2000;62:310-318.

19 De la Puente-Redondo VA, del Blanco NG, GutierrezMartin CB, et al. Comparison of different PCR approaches for typing of $F$. tularensis strains. J Clin Microbiol 2000;38:1016-1022.

20 Johansson A, Berglund L, Eriksson U, et al. Comparative analysis of PCR versus culture for diagnosis of ulceroglandular tularemia. J Clin Microbiol 2000;38: 22-26.

21 Karhukorpi EK, Karhukorpi J. Rapid laboratory diagnosis of ulceroglandular tularemia with polymerase chain reaction. Scand J Inf Dis 2001;33:383-385.

22 Gallivan MVE, Davis II WA, Garagusi VF, et al. Fatal cat-transmitted tularemia: demonstration of the organism in tissue. South Med J 1980;73:240-242.

23 Zaidi SA, Singer C. Gastrointestinal and hepatic manifestations of tickborne diseases in the United States. Clin Inf Dis 2002;34:1206-1212.

24 Sjostedt A, Kuoppa K, Johansson T, et al. The $17 \mathrm{kDa}$ lipoprotein and encoding gene of Francisella tularensis LVS are conserved in strains of Francisella tularensis. Microb Pathogenesis 1992;13: 243-249.
25 Berdal BP, Mehl R, Haaheim H, et al. Field detection of $F$ tularensis. Scand J Inf Dis 2000;32:287-291.

26 Bell JF, Stewart SJ. Chronic shedding tularemia nephritis in rodents: possible relation to occurrence of Francisella tularensis in lotic waters. J Wildlife Dis 1975;11:421-430.

27 Parker RR, Steinhaus EA, Kohls GM, et al. Contamination of natural waters and mud with Pasteurella tularensis and tularemia in beavers and muskrats in the northwestern United States. Natl Inst Health Bull 1951;193:1-61.

28 Shapiro DS, Schwartz DR. Exposure of laboratory workers to $F$ tularensis despite a bioterrorism procedure. J Clin Microbiol 2002;40:2278-2281.

29 Evans ME, Gregory DW, Schaffner W, et al. Tularemia: a 30 year experience with 88 cases. Medicine 1985;64:251-269.

30 Guerrant RL, Humphries Jr MK, Butler JE, et al. Tickborne oculoglandular tularemia: case report and review of seasonal and vectorial associations in 106 cases. Arch Int Med 1976;136:811-813.

31 Avery FW, Barnett TB. Pulmonary tularemia. A report of five cases and a consideration of pathogenesis and terminology. Am Rev Resp Dis 1967;95:584-591.

32 Baskerville A, Hambleton P, Dowsett AB. The pathology of untreated and antibiotic-treated experimental tularemia in monkeys. Br J Exp Pathol 1978;59 615-623.

33 Penn RL, Kinasewitz GT. Factors associated with a poor outcome in tularemia. Arch Intern Med 1987;147:265-268.

34 Baskerville A, Hambleton P. Pathogenesis and pathology of respiratory tularemia in the rabbit. Br J Exp Pathol 1976;57:339-347.

35 Sutinen S, Syrjala H. Histopathology of human lymph node tularemia caused by $F$. tularensis var palaearctica. Arch Pathol Lab Med 1986;110:42-46.

36 Pittman T, Williams D, Friedman AD. A shunt infection caused by $F$. tularensis. Pediatr Neurosurg 1996;24:50-51.

37 Buchanan TM, Brooks GF, Brachman PS. The tularemia skin test: 325 skin tests in 210 persons: serologic correlation and review of the literature. Ann Intern Med 1971;74:336-343.

38 Robinson-Dunn B. The microbiology laboratory's role in response to bioterrorism. Arch Pathol Lab Med 2002;126:291-294. 